\title{
Contribuições de Recursos Humanos para a Competitividade em Qualidade: Estudo de Casos
}

\author{
Fernando César Almada Santos \\ Luís Cesar Ribeiro Carpinetti \\ Marilson Alves Gonçalves
}

\section{ResUMO}

A inserção da gestão de recursos humanos na gestão da estratégia empresarial pode colaborar para o sucesso de programas de qualidade total, enfatizando-se as vantagens competitivas que podem ser criadas por essa parceria, tais como aprendizagem organizacional, gestão da cultura organizacional e organização baseada em equipes. Pesquisa exploratória em quatro empresas manufatureiras, líderes em seus mercados e de médio e grande porte da região central do Estado de São Paulo, permite demonstrar como o programa de recursos humanos pode contribuir para a efetividade de programas de qualidade total. Para a realização desta pesquisa, os principais elementos da gestão de recursos humanos e qualidade são analisados tanto pelo nível de implantação, como pela importância estratégica para a consecução da estratégia empresarial.

Palavras-chaves: qualidade total, recursos humanos, aprendizagem organizacional, manufatura.

\begin{abstract}
This paper presents an exploratory research carried out in four manufacturing companies (large to medium size) located in the central region of São Paulo State, Brazil. The research was conducted aiming at characterising the companies in regarding to quality and human resource management practices. The results evidence that inclusion of human resource management in the entrepreneurial strategic management may co-operate with the success of total quality programmes, emphasising the competitive advantages which can be created from this partnership, namely organisational learning, organisational culture management and team-based management. The main elements of human resource and quality management had both their rate of importance to the consecution of business strategy and intensity of application analysed.
\end{abstract}

Keywords: total quality management, human resource management, organisational learning, manufacturing. 


\section{INTRODUÇÃO}

A virada dos anos 90 exigiu do Brasil a transição para uma política de incentivo à competitividade industrial. Seguindo a tendência global, muito tem-se investido na qualidade como forma de reduzir custos e tempos de ciclo, incrementar vendas e aumentar a lucratividade dos negócios. O crescimento exponencial de certificações ISO 9.000 é prova disso (Gomes e Osório, 1995).

Migrar para uma política de incentivo à competitividade, centrada na qualidade, significa adesão a princípios e programas de focalização no cliente, de melhoria contínua e de capacitação de recursos humanos, elementos estruturais de gerenciamento da qualidade (Juran e Gryna, 1993). A não adesão organizacional a esses elementos explica muitos dos insucessos na implantação de programas da qualidade no Brasil e no exterior. O desenvolvimento de parcerias entre as áreas de recursos humanos e as demais áreas funcionais e enriquecimento das atividades tradicionais de gestão de recursos humanos, como o recrutamento, a seleção, a remuneração, a descrição e análise de cargos, o treinamento, o desenvolvimento gerencial e planejamento de sucessão (Mabey e Salaman, 1995) podem colaborar para redução desses insucessos. Essas parcerias desempenham papel decisivo no reposicionamento da gestão de recursos humanos como área de capital importância na formulação e na implementação de estratégias competitivas, centradas na qualidade.

Este artigo avalia o processo de implementação de políticas e programas de qualidade em quatro empresas manufatureiras localizadas na região central do Estado de São Paulo; constitui exemplo a ser estudado por outras organizações brasileiras na cruzada pela busca de competitividade em nível global. Pode-se antecipar que as conclusões deste estudo não permitem uma extensão incondicional destas a outros grupos de empresas, tais como do interior de São Paulo, do setor mecânico ou de empresas multinacionais no interior de São Paulo. Em outras palavras, realizou-se pesquisa de natureza exploratória, que aborda a gestão de recursos humanos em empresas específicas.

\section{Referencial Conceitual}

Desinteresse do nível gerencial, treinamento precário, sistema de remuneração 
inconsistente, descuido com a motivação e tantos outros fatores (Tolovi, 1994; Scully, 1996) muitas vezes são sintomas da pouca ênfase dada a políticas e programas de reposicionamento de cultura organizacional, de adoção de novas formas de gerenciamento e de aprendizagem organizacional.

As seguintes ações estratégicas em gestão de recursos humanos (Figura 1) colaboram para a consecução da qualidade total:

- inserção de recursos humanos na gestão estratégica dos negócios, exigindo de seus profissionais uma compreensão aprofundada dos negócios e capacidade de descentralização das decisões sobre atividades tradicionais para pessoal de linha das unidades de negócios;

- criação de ambiente propício a mudanças e aprendizagem organizacional, como um dos pré-requisitos para a inovação organizacional e tecnológica. Ao invés de treinar para trabalhos repetitivos, a gestão de recursos humanos deve colaborar para um clima de permanente renovação organizacional;

- gestão da cultura organizacional, transformando a gestão de recursos humanos em mais um agente dos processos de mudança organizacional; antes de se mudarem processos administrativos e métodos de trabalho, faz-se necessário mudar valores da organização em nível dos artefatos visíveis, em nível dos valores que governam comportamento das pessoas, ou ainda em nível dos pressupostos inconscientes (Fleury, 1989);

- constituição e fortalecimento do trabalho em equipe, objetivando a criação de uma visão global dos negócios em todos os processos de trabalho organizacionais, desde equipes em células de fabricação até as de engenharia simultânea e dos processos de negócios.

\section{Figura 1: Gestão Estratégica de Recursos Humanos}

\begin{tabular}{|c|c|}
\hline $\begin{array}{c}\text { Inserção na gestão estratégica } \\
\text { de negócios }\end{array}$ & Organização baseada em equipes \\
$\qquad \begin{array}{c}\text { GESTÃO ESTRATÉGICA DE } \\
\text { RECURSOS HUMANOS }\end{array}$ \\
\hline $\begin{array}{c}\text { Aprendizagem organizacional } \\
\text { Gestão da cultura organizacional }\end{array}$ \\
\hline
\end{tabular}




\section{Estudo de CASOS}

Procurando-se identificar interfaces ou fronteiras entre a gestão estratégica de negócios e as suas estratégias funcionais, quatro empresas manufatureiras, localizadas na região central do Estado de São Paulo, foram objeto de pesquisa intencional de caráter exploratório (Tabela 1).

A intencionalidade da amostra foi construída com base nas seguintes características:

- empresas manufatureiras do setor metal-mecânico;

- empresas líderes em seus mercados que estão enfrentando alto nível de concorrência;

- empresas com certificação ISO 9.000 .

A identidade destas empresas pode ser descrita pelos seguintes atributos de nacionalidade e de propriedade de capital:

- duas delas constituem a Divisão Brasil de empresas multinacionais norteamericanas (empresas A e B);

- uma delas caracteriza-se como representante das plantas industriais da Divisão Brasil de empresa multinacional sueca (empresa C); porém a Divisão Brasil originou-se da aquisição de uma empresa brasileira em 1994;

- uma delas é matriz de empresa originariamente brasileira (empresa D), que além das unidades de negócios alocadas junto à matriz, possui outras no Brasil e no exterior. Esta empresa, em particular, já é detentora de certificação QS 9.000 .

Tabela 1: Caracterização das Empresas Pesquisadas

\begin{tabular}{|c|c|c|c|}
\hline \multirow{2}{*}{ Empresa } & \multicolumn{3}{|c|}{ Características } \\
\cline { 2 - 4 } & $\begin{array}{c}\text { Principais } \\
\text { Bens/Produtos }\end{array}$ & $\begin{array}{c}\text { n. de funcionários/ } \\
\text { porte }\end{array}$ & $\begin{array}{c}\text { Faturamento } \\
\text { (US\$ milhões) }\end{array}$ \\
\hline A & de capital & $2.600 /$ grande & mais de 150 \\
\hline B & de capital & $290 /$ médio & entre 25 e 50 \\
\hline C & de consumo duráveis & $2.400 /$ grande & mais de 150 \\
\hline D & autopeças & $2.140 /$ médio & mais de 150 \\
\hline
\end{tabular}


Quanto à investigação realizada nas empresas, profissionais de alta e média gerência foram entrevistados; observe-se que essas pessoas possuíam simultaneamente visão histórica e estratégica das seguintes áreas: planejamento ou gestão estratégica, gestão de recursos humanos, gestão da qualidade, engenharia de produto e de processo e planejamento e controle da produção ou logística. Paralelamente às entrevistas realizaram-se visitas técnicas a cada uma das áreas, objetivando a visualização de sistemas e dinâmica das respectivas áreas. Trabalhou-se com entrevistas direcionadas às questões específicas; a seguir criava-se oportunidade para que os entrevistados emitissem informações complementares sobre a área.

Para a caracterização das áreas da qualidade e de recursos humanos, os entrevistados foram solicitados a indicar intensidade de aplicação de conceitos e/ou metodologias e a importância deles para a consecução da estratégia empresarial (Tabelas 2 e 3 ).

\section{Tabela 2: Intensidade de Aplicação de Elementos de Recursos Humanos e Qualidade}

\begin{tabular}{|c|l|}
\hline $\begin{array}{c}\text { Intensidade de } \\
\text { Aplicação }\end{array}$ & \multicolumn{1}{c|}{ Significado } \\
\hline 0 & Não se conhece a técnica, o programa ou o conceito. \\
\hline 1 & Nada foi feito, pois não temos interesse. \\
\hline 2 & Nada foi feito, pois o custo de implantação é alto. \\
\hline 3 & $\begin{array}{l}\text { Estudos já foram feitos, estando em via de } \\
\text { implantação. }\end{array}$ \\
\hline 4 & $\begin{array}{l}\text { Tentativas foram feitas, mas o programa está parado } \\
\text { no momento. }\end{array}$ \\
\hline 5 & Está implantado parcialmente. \\
\hline 6 & $\begin{array}{l}\text { Está totalmente implantado e funcionando, } \\
\text { aperfeiçoamentos futuros serão pequenos. }\end{array}$ \\
\hline
\end{tabular}


Tabela 3: Importância da Implantação dos Elementos de Recursos Humanos e Qualidade para a Consecução da Estratégia Empresarial

\begin{tabular}{|l|l|}
\hline \multicolumn{2}{|c|}{ Importância para a consecução da estratégia empresarial } \\
\hline A & De grande valor \\
\hline B & Proporcionou bons resultados \\
\hline C & Colaborações mínimas \\
\hline D & Em nada colaborou \\
\hline E & Tal elemento gerou problemas internos \\
\hline
\end{tabular}

\section{Elementos da Gestão da Qualidade presentes na Gestão de Empresas Manufatureiras}

As Tabela 4A e 4B apresentam a intensidade de aplicação e o grau de importância para a consecução da estratégia empresarial relativas a conceitos de qualidade total, desenvolvimento de fornecedores, programas de melhoria contínua, e ferramentas e metodologias para o planejamento, controle e melhoria da qualidade. Os principais elementos exigidos durante a implementação da qualidade total e durante a certificação ISO 9.000 estão presentes em todas as empresas pesquisadas:

- desenvolvimento de fornecedores em qualidade;

- controle estatístico de processo;

- programa de melhoria contínua;

- análise dos modos e efeitos de falha;

- manutenção preventiva. 


\section{Tabela 4A: Caracterização da Gestão da Qualidade nas Empresas Pesquisadas}

\begin{tabular}{|c|c|c|c|c|}
\hline Empresa & $\begin{array}{c}\text { Desenvolvimento } \\
\text { de Fornecedores } \\
\text { em Qualidade }\end{array}$ & $\begin{array}{c}\text { Controle } \\
\text { Estatístico de } \\
\text { Processo - CEP }\end{array}$ & $\begin{array}{c}\text { Programa de } \\
\text { melhoria contínua } \\
\text { Kaizen }\end{array}$ & $\begin{array}{c}\text { Análise do Modos } \\
\text { e Efeitos de Falha } \\
\text { FMEA }\end{array}$ \\
\hline A & $6 \mathrm{~A}$ & $6 \mathrm{~A}$ & $6 \mathrm{~A}$ & $6 \mathrm{~A}$ \\
\hline $\mathrm{B}$ & $5 \mathrm{~A}$ & $3 \mathrm{~B}$ & $5 \mathrm{~A}$ & $5 \mathrm{~A}$ \\
\hline $\mathrm{C}$ & $6 \mathrm{~A}$ & $5 \mathrm{~A}$ & $6 \mathrm{~A}$ & $6 \mathrm{~A}$ \\
\hline $\mathrm{D}$ & $6 \mathrm{~B}$ & $6 \mathrm{~B}$ & $6 \mathrm{~A}$ & $5 \mathrm{~B}$ \\
\hline
\end{tabular}

Tabela 4B: Caracterização da Gestão da Qualidade nas Empresas Pesquisadas

\begin{tabular}{|c|c|c|c|c|c|}
\hline Empresa & $\begin{array}{c}\text { Desmembramento } \\
\text { da Função } \\
\text { Qualidade - QFD }\end{array}$ & $\begin{array}{c}\text { Planejamento } \\
\text { Experimentos }\end{array}$ & $\begin{array}{c}\text { Manutenção } \\
\text { Preventiva }\end{array}$ & $\begin{array}{c}\text { Manutenção } \\
\text { Preditiva }\end{array}$ & $\begin{array}{c}\text { Manutenção } \\
\text { Produtiva } \\
\text { Total - MPT }\end{array}$ \\
\hline A & $6 \mathrm{~A}$ & $6 \mathrm{~A}$ & $6 \mathrm{~A}$ & $6 \mathrm{~A}$ & $6 \mathrm{~A}$ \\
\hline $\mathrm{B}$ & $3 \mathrm{~A}$ & $3 \mathrm{~B}$ & $6 \mathrm{~A}$ & $6 \mathrm{~A}$ & $5 \mathrm{~A}$ \\
\hline $\mathrm{C}$ & $3 \mathrm{~B}$ & $4 \mathrm{~B}$ & $5 \mathrm{~A}$ & $3 \mathrm{~B}$ & $3 \mathrm{~B}$ \\
\hline $\mathrm{D}$ & $4 \mathrm{~B}$ & $4 \mathrm{~B}$ & $5 \mathrm{~A}$ & $4 \mathrm{~B}$ & $4 \mathrm{~B}$ \\
\hline
\end{tabular}

Porém algumas especificidades devem ser notadas:

- a metodologia quality function deployment - QFD - e o planejamento de experimentos são praticados em toda a sua potencialidade somente pela empresa A;

- programas de manutenção preditiva e produtiva total também só eram executados pelas empresas $\mathrm{A} e \mathrm{~B}$, não só internamente às empresas, mas por estas dedicarem suficientes esforços nos serviços de assistência técnica aos clientes. 
Deve-se ressaltar que as empresas A, B e C procuravam melhorar a qualidade do produto e da produção a partir de enfoques do usuário. Isto não ocorria para a empresa $\mathrm{D}$, por essa ser fornecedora de autopeças rigidamente especificadas pelas montadoras.

\section{Elementos da Gestão de Recursos Humanos presentes na Gestão de Empresas Manufatureiras}

As Tabela 5A e 5B, a seguir, apresentam a intensidade de aplicação e o grau de importância para a consecução da estratégia empresarial relativas a conceitos em recursos humanos.

Em todas as empresas têm-se os seguintes elementos praticados:

· inserção de recursos humanos na gestão dos negócios das empresas;

· constituição de recursos humanos como consultoria interna;

· programas de educação continuada;

· apoio à formação de equipes;

- monitoração do clima organizacional, o que consta da análise das principais satisfações e insatisfações das pessoas em seu ambiente de trabalho; no caso da empresa A, a análise anual do clima organizacional era feita para todas as unidades de negócios da corporação;

- mudança cultural, o que acontece pela necessidade das empresas em mudar os valores da cultura organizacional, por meio de seus funcionários, tornando-a compatível com determinada estratégia.

Como elementos aplicados somente pelas empresas A, B e D têm-se:

- recursos humanos como viabilizadores da transparência administrativa em toda a organização;

- formação de empreendedores, notada pela multidisciplinaridade do conteúdo dos programas de treinamento (Tabelas 7 e 8);

- avaliação do desempenho dos indivíduos, das equipes, das unidades de negócio e da empresa; deve-se lembrar que nas demais empresas a avaliação de desempenho não constava de todos esses aspectos, principalmente da avaliação individual; 
· autocontrole dos funcionários;

· orientação e comunicação maciças, observando-se que na empresa A, além das formas tradicionais de comunicação, enviavam-se mensagens eletrônicas de natureza estratégica por toda a empresa.

\section{Tabela 5A: Caracterização da Gestão de Recursos Humanos nas Empresas Pesquisadas}

\begin{tabular}{|c|c|c|c|c|c|}
\hline Empresa & $\begin{array}{c}\text { Ligação de } \\
\text { RH } \\
\text { com negócios }\end{array}$ & $\begin{array}{c}\text { RH como } \\
\text { consultoria } \\
\text { interna }\end{array}$ & $\begin{array}{c}\text { Educação } \\
\text { continuada }\end{array}$ & $\begin{array}{c}\text { Apoio à } \\
\text { formação } \\
\text { de equipes }\end{array}$ & $\begin{array}{c}\text { Transparência } \\
\text { administrativa }\end{array}$ \\
\hline A & $5 \mathrm{~A}$ & $5 \mathrm{~B}$ & $5 \mathrm{~B}$ & $6 \mathrm{~A}$ & $6 \mathrm{~A}$ \\
\hline $\mathrm{B}$ & $6 \mathrm{~A}$ & $6 \mathrm{~A}$ & $6 \mathrm{~A}$ & $6 \mathrm{~A}$ & $6 \mathrm{~A}$ \\
\hline $\mathrm{C}$ & $5 \mathrm{~B}$ & $6 \mathrm{~B}$ & $6 \mathrm{~A}$ & $5 \mathrm{~A}$ & $4 \mathrm{~B}$ \\
\hline $\mathrm{D}$ & $6 \mathrm{~A}$ & $6 \mathrm{~A}$ & $6 \mathrm{~A}$ & $6 \mathrm{~A}$ & $6 \mathrm{~A}$ \\
\hline
\end{tabular}

\section{TABELA 5B - Caracterização da Gestão de Recursos Humanos nas Empresas Pesquisadas}

\begin{tabular}{|c|c|c|c|c|c|c|}
\hline Empresa & $\begin{array}{c}\text { Formação de } \\
\text { empreendedores }\end{array}$ & $\begin{array}{c}\text { Ampla } \\
\text { Avaliação } \\
\text { desempenho }\end{array}$ & $\begin{array}{c}\text { Mudança } \\
\text { cultural }\end{array}$ & $\begin{array}{c}\text { Autocontrole } \\
\text { dos } \\
\text { funcionários }\end{array}$ & $\begin{array}{c}\text { Monitoração } \\
\text { do clima } \\
\text { organizacional }\end{array}$ & $\begin{array}{c}\text { Orientação e } \\
\text { comunicação } \\
\text { intensivas }\end{array}$ \\
\hline $\mathrm{A}$ & $5 \mathrm{~A}$ & $6 \mathrm{~A}$ & $5 \mathrm{~A}$ & $6 \mathrm{~A}$ & $6 \mathrm{~A}$ & $6 \mathrm{~A}$ \\
\hline $\mathrm{B}$ & $5 \mathrm{~A}$ & $6 \mathrm{~A}$ & $5 \mathrm{~A}$ & $6 \mathrm{~A}$ & $6 \mathrm{~A}$ & $6 \mathrm{~A}$ \\
\hline $\mathrm{C}$ & $4 \mathrm{~A}$ & $4 \mathrm{C}$ & $5 \mathrm{~B}$ & $4 \mathrm{~B}$ & $6 \mathrm{~A}$ & $4 \mathrm{~B}$ \\
\hline $\mathrm{D}$ & $6 \mathrm{~A}$ & $6 \mathrm{~A}$ & $6 \mathrm{~A}$ & $6 \mathrm{~A}$ & $5 \mathrm{~B}$ & $6 \mathrm{~A}$ \\
\hline
\end{tabular}

Como ainda fatores que diferenciam empresas A, B e D (não apresentados em tabela), pode-se elencar:

- existência de multiplicadores de treinamento em todos os níveis hierárquicos das empresas; 
- a visualização da importância da qualidade, do trabalho em equipe e da educação continuada pelo corpo gerencial.

\section{Discussão dos Resultados}

Primeiramente, deve-se observar que as empresas A e B possuíam nível de inovação em seus produtos e respectivos modelos significativamente maior do que as empresas C e D. Por outro lado, as empresas C e D reduziram prazos de entrega e aumentaram capacidade e volume de produção de forma mais destacada que as empresas A e B. Além disso, uma importante distinção a ser feita entre as empresas $\mathrm{C}$ e $\mathrm{D}$ é que a primeira direcionava seus produtos para o mercado regional, especificamente Mercosul, enquanto a segunda tinha seus produtos comercializados em mercados globais.

Sinteticamente pode-se afirmar que as empresas A e B adotaram flexibilidade, especificamente relacionada à inovação de produtos e serviços e à diversificação do mix como prioridade competitiva da estratégia da manufatura. Por sua vez, as empresas $\mathrm{C}$ e $\mathrm{D}$ optaram pelo desempenho de entregas como prioridade competitiva. Vale frisar que todas as empresas pesquisadas buscaram redução de custo e qualidade, cada qual à sua moda.

Para a obtenção de resultados satisfatórios na gestão de seus negócios, pode-se observar a ocorrência de mudanças organizacionais dentro das empresas, que viabilizaram o sucesso das estratégias assumidas pelas empresas. Assim, ocorreu a redução de dois a três níveis hierárquicos nos últimos cinco anos em todas as empresas pesquisadas. Os níveis eliminados eram ocupados por gerentes de nível médio com função de supervisão.

Outra mudança importante foi a transformação de departamentos funcionais (recursos humanos, qualidade e planejamento e controle da produção) em áreas de apoio aos negócios, e a transformação da engenharia de processo (envolvendo ou não a engenharia de produto) em funções-chaves das unidades de negócios.

Quanto à gestão da qualidade, as respostas apresentadas nas Tabelas 4A e 4B, indicam que as empresas pesquisadas, de modo geral, consideram de grande importância, ou tendo proporcionado bons resultados para a consecução da estratégia empresarial, a aplicação de metodologias de planejamento, controle e melhoria da qualidade, ou seja, a estratégia empresarial delas, das quais decorrem as estratégias de manufatura, evidentemente priorizam a qualidade como fator competitivo. 
Outro aspecto a destacar é que dentre as metodologias e técnicas consideradas nesta pesquisa, algumas delas estão totalmente implantadas (todas na empresa A), parcialmente implantadas ou em vias de implantação (empresa B, para quatro das metodologias consideradas, e a empresa $\mathrm{C}$ para duas metodologias). Em outras palavras, as empresas pesquisadas podem ser caracterizadas como empresas detentoras de programas da qualidade com certo grau de amadurecimento e que, principalmente, deram certo; caso contrário, a aplicação dessas metodologias presumivelmente já teria sido abandonada, e elas deixariam de ser importantes para o cumprimento das diretrizes estratégicas.

Com relação à prática da gestão dos recursos humanos, apresentada nas Tabelas $5 \mathrm{~A}$ e $5 \mathrm{~B}$, percebe-se que as empresas, predominantemente, consideram como de grande valor ou tendo propiciado bons resultados para a consecução da estratégia empresarial, elementos como apoio à formação de equipes, formação de empreendedores, monitoração do clima organizacional, orientação e comunicação intensivas, autocontrole dos funcionários, o papel da gestão de recursos humanos no processo de mudança cultural, a atuação desta área como consultoria interna e como viabilizadora da transparência administrativa. As repostas sugerem também que a prática desses conceitos está totalmente ou parcialmente implantada, ou, em alguns casos, em processo de implantação.

Percebe-se que, nas empresas pesquisadas, a área de recursos humanos tem sob sua responsabilidade não só as atividades tradicionais (recrutamento, seleção, remuneração, benefícios etc): ou seja, existe parceria com outras áreas, fundamentais para programas da qualidade, tais como formação de empreendedores, formação de equipes, monitoração do clima organizacional, entre outras, que são geridas com a assessoria de recursos humanos. A parceria dessa área com as demais áreas funcionais é evidenciada pelas informações contidas na Tabela 6, em que se percebe que esta área, de modo geral, é no mínimo consultada sobre a viabilidade de implantação de programas de outras áreas e, em muitos casos, participa de forma ativa em programas das outras áreas.

Outro aspecto importante que diferencia as empresas pesquisadas é a abrangência do conteúdo dos programas de treinamento oferecidos não só ao corpo gerencial como também ao pessoal de chão de fábrica, conforme indicado nas Tabelas 7 e 8 , a seguir.

Sinteticamente, pode-se dizer que os elementos da gestão de recursos humanos das empresas A e B, cuja estratégia se volta para a inovação, são mais avançados do que o que se poderia esperar de empresas que adotam estratégias direcionadas ao desempenho de entregas, tais como as empresas $\mathrm{C}$ e D. No entanto a gestão de recursos humanos na empresa $\mathrm{D}$ possui a mesma sofisticação que em A e B. Uma explicação possível deve-se ao fato de D operar em mercados globais com produtos "mundiais". 

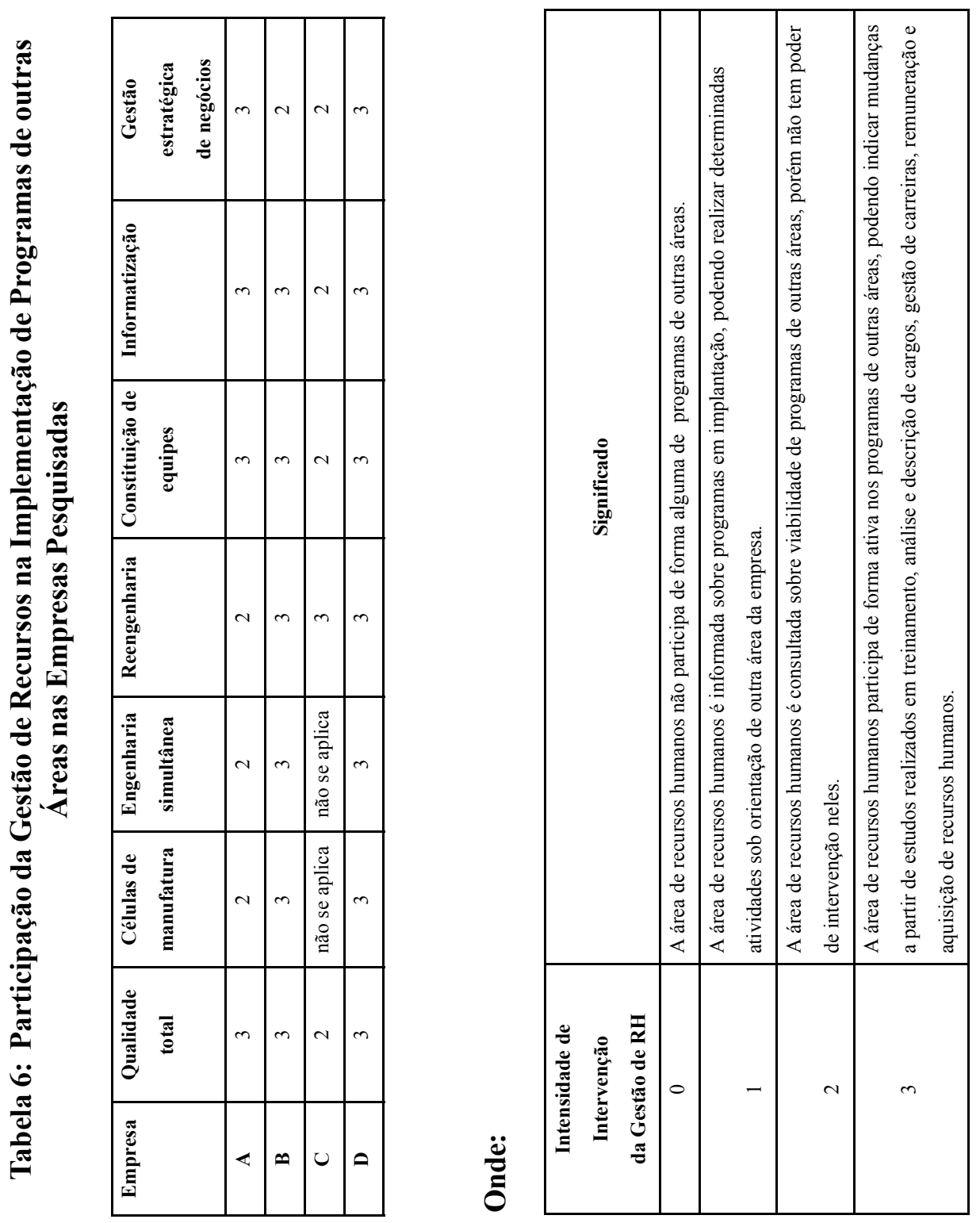


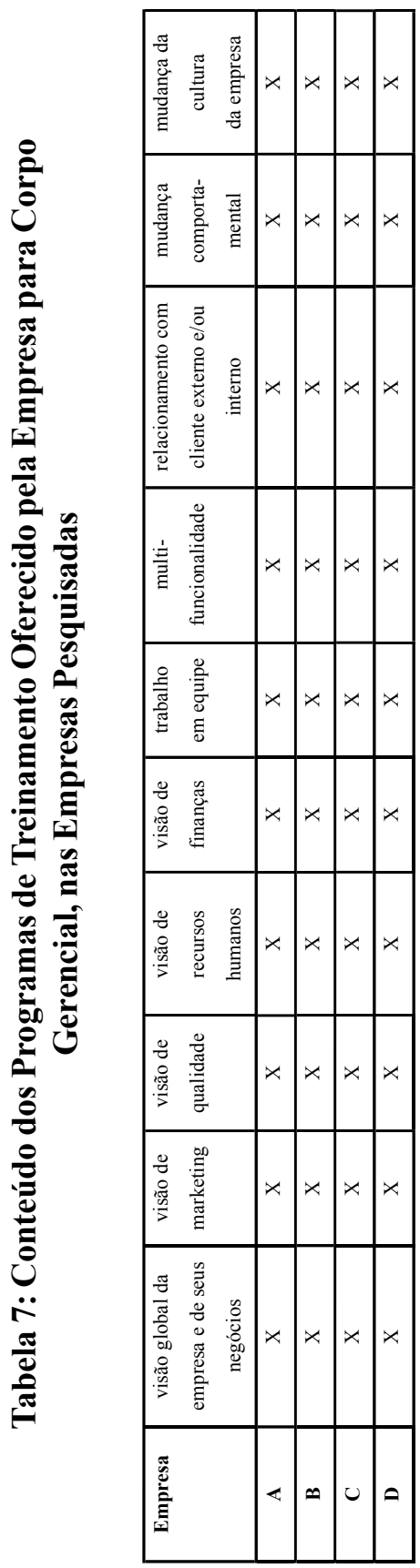

을

\begin{tabular}{|c|c|c|c|c|c|}
\hline 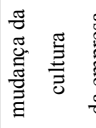 & 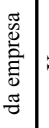 & $x$ & $x$ & 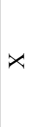 & $x$ \\
\hline 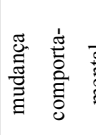 & 焉 & $x$ & $x$ & $x$ & $x$ \\
\hline 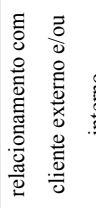 & . & $x$ & $x$ & $x$ & $x$ \\
\hline 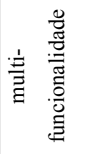 & & $x$ & $x$ & $x$ & $x$ \\
\hline 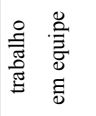 & & $x$ & $x$ & $x$ & $x$ \\
\hline 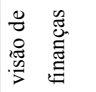 & & & $x$ & & \\
\hline 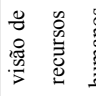 & 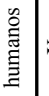 & $x$ & $x$ & & $x$ \\
\hline 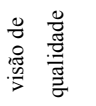 & & $x$ & $x$ & $x$ & $x$ \\
\hline 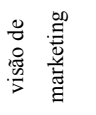 & & & $x$ & & \\
\hline 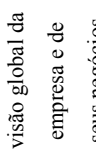 & $\begin{array}{l}0 \\
.0 \\
0 \\
0 \\
0 \\
0 \\
0 \\
0 \\
0 \\
0\end{array}$ & $x$ & $x$ & & $x$ \\
\hline 莺 & & $\varangle$ & ص & U & $\theta$ \\
\hline
\end{tabular}


Analisam-se em seguida os quatro aspectos estratégicos da gestão de recursos humanos que evidenciam as colaborações efetivas dessa área para o sucesso da gestão da qualidade total, que permite atuação conjunta dessas áreas na gestão estratégica de negócios.

\section{Inserção de Recursos Humanos e da Qualidade na Gestão Estratégica de Negócios}

Primeiramente cabe observar que as atuações das áreas de recursos humanos e de qualidade no processo de planejamento estratégico das empresas pesquisadas sempre se caracterizaram como participação efetiva. Em nenhum caso, essa atuação se restringiu à consulta ou à simples comunicação sobre decisões estratégicas tomadas.

A participação efetiva dos responsáveis por essas áreas na gestão de negócios permitia-lhes a conscientização dos objetivos estratégicos. Devido ao fato de as atividades tradicionais de recursos humanos e de qualidade terem sido descentralizadas parcialmente, os gerentes das unidades de negócios passaram a ser assessorados por funcionários dessas áreas. Na empresa $\mathrm{C}$, tinha-se até um funcionário de recursos humanos alocado diretamente nas unidades de negócios. Além de auxiliar as unidades de negócios no exercício de atividades de recursos humanos, outro papel importante era viabilizar a introdução de princípios estratégicos de recursos humanos na gestão dos negócios.

Nessa transformação da área de recursos humanos, ocorreu uma transferência das atividades de recursos humanos para a gerência de linha que, neste estudo de casos, eram as unidades de negócios. Assim, essas atividades eram de total responsabilidade da linha, a qual se servia do apoio técnico da área de recursos humanos. Juntamente com os funcionários da área de recursos humanos, funcionários das outras áreas funcionais assessoravam os gerentes das unidades de negócios, podendo até exercer funções de linha (Figura 2). Essa interação intersetorial, ocorrida durante negociações, possibilitou um conhecimento mútuo das estratégias das áreas funcionais da empresa. Assim, tornou-se possível o estabelecimento de objetivo comum, que consiste em uma das disciplinas da aprendizagem organizacional (Senge, 1993).

Para ratificar essa constatação, apresenta-se o envolvimento da gestão de recursos humanos em atividades e programas de outras áreas de organização na Tabela 6. Nota-se uma participação ativa da gestão de recursos humanos nas empresas pesquisadas, principalmente no que tange à viabilização de programas de outras áreas, tais como a qualidade total, certificação ISO 9.000 e constituição de equipes. No caso das empresas pesquisadas que mais inovam em termos organizacionais 
e tecnológicos (A, B e D), a gestão de recursos humanos participa de programas de engenharia simultânea, constituição de células de manufatura, reengenharia, informatização e gestão estratégica. Como curiosidade vale mostrar que na empresa $\mathrm{C}$, o ex-gerente de recursos humanos ocupava o cargo de gerência de uma unidade de negócios. De outro lado, na empresa A um ex-engenheiro de projeto e processos tornou-se responsável pela área de recursos humanos.

\section{Figura 2: Equipe Gestora das Unidades de Negócios}

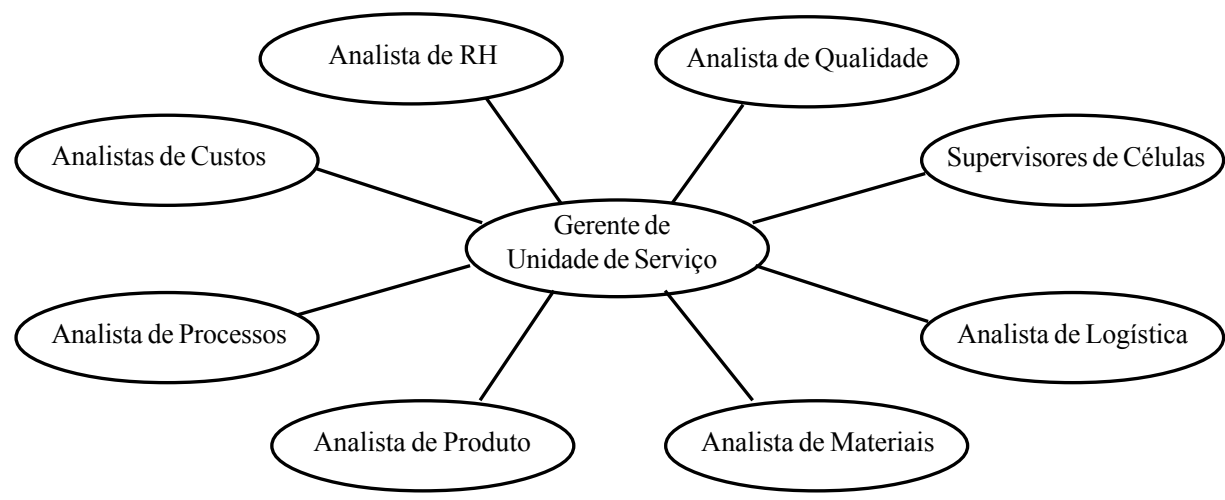

O passo posterior à definição de objetivos estratégicos é a sua disseminação por toda a organização, cuja condução nas empresas pesquisadas é apresentada nos tópicos posteriores.

\section{Aprendizagem Organizacional}

No atual momento de globalização, as empresas pesquisadas se mostraram conscientes da necessidade de inovação gerencial e tecnológica e, em decorrência, preocupadas com a aprendizagem organizacional. Apesar de somente as empresas A e C se mostrarem explicitamente preocupadas com a aprendizagem organizacional, todas as empresas utilizavam seus conceitos em sua gestão.

Como uma das preocupações centrais da aprendizagem organizacional tem-se a criação de postura estratégica por parte de todos os funcionários da organização. Senge (1993) postula que existem cinco disciplinas em que se baseia a criação e dinâmica de uma organização de aprendizagem: raciocínio sistêmico, domínio pessoal, objetivo comum, aprendizagem em grupo e modelos mentais. 
O raciocínio sistêmico é viabilizado principalmente pelos princípios organizacionais adotados pelas empresas. Dentro das unidades de negócios, os funcionários das várias áreas devem rever seus estereótipos e modelos mentais, para poderem negociar eficazmente a inserção de princípios de suas áreas na gestão estratégica de negócios. Não há como fazer isso, a não ser efetivamente trabalhando em grupo, o que exige prévia capacitação em termos de conhecimentos e técnicas multidisciplinares. Esse processo efetivamente acontecia em todas as empresas.

Ao promoverem a descentralização administrativa, as unidades de negócios se capacitaram em todas as facetas da gestão empresarial, ou seja, recursos humanos, qualidade, planejamento e controle da produção, gestão financeira e de custos industriais, relacionamento com clientes externos e informática. Foi imprescindível para essa descentralização um programa intenso e interdisciplinar de treinamento (Tabelas 7 e 8). Esse treinamento, aliado à existência de multiplicadores de treinamento, pode ser considerado fator fundamental para o fortalecimento do domínio pessoal, imprescindível para a constituição de equipes, pois uma das restrições do desempenho das equipes está na qualificação individual dos funcionários.

Em todas as empresas, mencionou-se a importância da preparação da organização para o processo de mudança, no sentido de viabilizar a mobilidade estratégica. Em outras palavras, ao se mudarem prioridades estratégicas do negócio, por exemplo de desempenho de entrega para flexibilidade de produto e satisfação de necessidades emergentes dos clientes, as pessoas devem ter condições para gerar tais mudanças. Na empresa $\mathrm{D}$, criou-se um programa voltado para a inovação em processos de trabalho em toda a empresa: certo grupo de pessoas pode elaborar proposta de mudança, aponta ganhos em qualidade e recursos humanos e redução de prazos e custos, tendo recompensa proporcional em salário. Esse fato pode ser interpretado como auto-reengenharia, durante a qual os próprios funcionários da empresa se encarregam de realizar a mudança organizacional. Complementarmente, as empresas utilizavam-se freqüentemente do benchmarking interno, para disseminar conceitos, programas e técnicas utilizadas com sucesso por equipes administrativas, células de produção e unidades de negócios.

Como prática da aprendizagem tecnológica, que complementava a aquisição de tecnologia da matriz ou compra de tecnologia, tem-se a estruturação de laboratórios para adaptação de produtos para as condições de uso e de manutenção no mercado nacional nas empresas A, C e D. A empresa B desenvolvia determinados produtos e adquiria tecnologia de outros. Mesmo no caso de aquisição de tecnologia externa, todas as empresas mostraram conhecer o estado da arte da tecnologia básica de seus produtos, o que evidencia maturação na gestão de tecnologia. 
A partir da constatação da presença das cinco práticas de aprendizagem organizacional conceituadas por Garvin (1993) - resolução sistemática de problemas, experimentação, análise de experiências passadas, circulação de conhecimento e aproveitamento de experiências realizadas por outros - podem-se considerar as empresas pesquisadas como organizações de aprendizagem.

\section{Organizações Baseadas em Equipes}

Ao se voltar para a estratégia das unidades de negócios, a gestão de recursos humanos deve buscar uma estruturação da organização em equipes e a eliminação de barreiras departamentais e de grupos específicos. Efetivamente foi isso que ocorreu nas empresas pesquisadas.

$\mathrm{Na}$ empresa $\mathrm{D}$, as áreas de engenharia tradicionais (projeto, processos e produção) foram transformadas em gerências de marketing e tecnologia e unidades de negócios. Não havia vinculação de especialistas em determinada área de conhecimento à área funcional da empresa. Em todas as empresas vigorava o princípio das competências essenciais (Hamel e Prahalad, 1995). Nem sempre conscientes disto, as pessoas se reuniam e/ou eram reunidas para a realização ou melhorias de determinado projeto ou processo em todos os níveis e áreas da organização. Além disso, pode-se dizer que todas as empresas se constituíram em organizações baseadas em equipes (Tabela 9), observando-se que as equipes operavam sempre em mais que um nível hierárquico nas empresas pesquisadas.

\section{Tabela 9: Participação dos Funcionários de Diferentes Níveis Hierárquicos em Equipes}

\begin{tabular}{|c|c|}
\hline Nível Hierárquico & Participação em Equipes \\
\hline Cúpula Administrativa & Processos de Negócios \\
& Engenharia Simultânea \\
\hline Média Gerência & Processos de Negócios \\
& Redefinição de Processos de Negócios \\
& Engenharia Simultânea \\
\hline Piso de Fábrica & Redefinição de Processos \\
& Kaizen \\
& Engenharia Simultânea \\
\hline
\end{tabular}




\section{Gestão da Cultura Organizacional}

Os gerentes entrevistados nas empresas, os quais realizavam atividades em gestão estratégica, apontaram para o fato de que as mudanças intensas e diversificadas (mercado, tecnologia, legislação e política governamental) exigiam a incorporação de novos valores dentro da organização mediante a introdução de conceitos organizacionais, tecnologias e novas formas de organização. Porém a assimilação desses valores depende em muito das características específicas de cada empresa. Assim, fazia-se necessária uma constante monitoração da cultura e do clima organizacional.

Certo gerente da empresa A sentia-se responsável pela mudança cultural dentro da organização, observando quão abstrata era essa função e sua imprescindibilidade para o sucesso dos negócios da empresa. Outro gerente, da empresa $\mathrm{C}$, evidenciou a preocupação de estar acompanhando sempre a assimilação das modas em administração e tecnologia na organização, porque cada pessoa e cada grupo podem materializar conceitos de forma muito diversa, e as vezes um conceito pode ser totalmente incompatível com a realidade da empresa.

Por parte das gerências, merecia cuidado a excessiva ênfase em tecnologia que funcionários de empresas manufatureiras costumam direcionar para a gestão de negócios. Frisava-se sempre a importância de se incorporar conceitos diversos em gestão de negócios, posição esta que ratifica o posicionamento de Wassenhove e Cobertt (1991): "quando todas as empresas tiverem acesso a mesma tecnologia flexível o único fator diferencial entre as empresas serão os recursos humanos". Assim uma empresa que não for capaz de aumentar o conhecimento de seus funcionários e de garantir o seu bem-estar, de modo que esses contribuam para o seu bom funcionamento, pode não sobreviver, ainda que possua vantagem competitiva de natureza tecnológica.

A necessidade de as empresas mudarem os valores da cultura organizacional, por meio de seus funcionários, para torná-la compatível com determinada estratégia é notadamente percebida pelo fato de que a metade dos programas de treinamento e desenvolvimento gerencial, em média, atendem às necessidades globais da organização. Sempre esteve presente a preocupação em incorporar valores como equidade, franqueza nas comunicações, satisfação de clientes, senso de urgência, atualização profissional, empregabilidade e inovação tecnológica. 


\section{Consideraçóes Finals}

Conclui-se que, independentemente das mudanças empreendidas por recursos humanos e qualidade conjuntamente com outras áreas funcionais, as empresas se preocuparam com a consistência global do processo de mudança, repensando de forma holística a estratégia de manufatura, a estrutura organizacional, os conhecimentos e habilidades técnicas, as sistemáticas de aprendizagem e resolução de problemas e a cultura organizacional. Essa reestrututuração das empresas teve como principais preocupações: a inserção das várias áreas funcionais na gestão estratégica de negócios, a constituição de equipes voltadas para os diversos aspectos dos negócios, a aprendizagem organizacional e a gestão da cultura organizacional.

A partir dessa transformação, as empresas pesquisadas alcançaram a competitividade pela qualidade, sempre aliada à mobilidade estratégica que lhes permitiam equilibrar continuamente as prioridades competitivas em inovação, desempenho de entregas e custos.

\section{ReferênCias Biblogáficas}

FLEURY, M. T. L.

O desvendar a cultura de uma organização - uma discussão metodológica. In: FLEURY, M. T. L.; FISCHER, R. (Coord.). Cultura e poder nas organizacões. São Paulo: Atlas, 1989. p.15-27.

GARVIN, D. A.

Building a learning organization. Harvard Business Review, v. 81, n.4, p.78-91, July/Aug. 1993.

GOMES, E. R.; OSÓRIO, P. M.

ISO 9.000 : o que muda com a revisão. Controle da Qualidade, n.40, set. 1995

HAMEL, G.;

PRAHALAD, C. K.

Competindo pelo futuro : estratégias inovadoras para obter o con- trole do seu setor e criar mercados de amanhã. Rio de Janeiro : Campus, 1995.

JURAN, J. M.;

GRYNA, F.

Quality analysis and planning. New York: McGraw-Hill, 1993.

MABEY, C.;

SALAMAN, G.

Strategic human resource management. London : Blackwell, 1995.

SCULLY, J. P. TQM and human nature : getting beyond organizational misconceptions.

Progress, May 1996. 
SENGE, P.

A quinta disciplina : arte, teoria e prática da organização de aprendizagem. 5.ed. São Paulo : Best Seller, 1993.

TOLOVI, J.

Por que os programas de qualidade falham? Revista de Administração de Empresas, v.34, n.6, nov./dez. 1994.

WASSENHOVE, L. N.;

CORBETT, C. J.

Trade-offs? What trade-offs?

Working Paper. Insead, 1991. $20 \mathrm{p}$. 